\title{
A Mobile App to Replace the Goniometer? A Pilot Study Focusing on the Measurement of Knee Range of Movement
}

\author{
Sara Aspinall ${ }^{1,2}$, Tim Sparks ${ }^{3}$, Andrew King ${ }^{4}$, Mike Price ${ }^{4}$ and Steven Godsiff ${ }^{2}$ \\ 1. School of Sport, Exercise and Health Sciences, Loughborough University, Loughborough, LE11 3TU- UK \\ 2. University Hospitals of Leicester NHS Trust, Leicester, LE1 5WW -England, UK \\ 3. Faculty of Engineering and Computing, Coventry University, Coventry, CV1 5RW, England, UK \\ 4. Faculty of Health and Life Sciences, Coventry University, Coventry, CV1 5RW, England, UK
}

\begin{abstract}
Abstact: Background: The universal goniometer is commonly used to measure knee range of movement in clinical practice. However, research has demonstrated that the universal goniometer lacks reliability failing to meet the standard of clinically acceptable error $\left(5^{\circ}\right)$. Objective: This study tested the concurrent validity and intra-rater reliability of a photographic based “app” developed for feedback in sport, the Hudl Ubersense App, as an alternative instrument for measuring knee range of movement. Methods: Measurements of knee range of movement were made concurrently with the electrogoniometer (the gold standard) and the Hudl Ubersense App across a pre-determined randomised set of 20 functional knee angles between $35^{\circ}$ and $130^{\circ}$. This was then repeated. The pre-agreed standard of concurrent validity was that $95 \%$ of Hudl Ubersense App measurements would be within $5^{\circ}$ of the electrogoniometer and differences were displayed in Bland-Altman plots. Results: Thirty nine (97\%) of the forty app readings differed from the corresponding electrogoniometer readings by less than $5^{\circ}$. The mean differences between the electrogoniometer and Hudl Ubersense App measurements over each trial were $1.75^{\circ}$ and $0.80^{\circ}$ respectively, indicating a high level of concurrent validity. There was less than $1.0^{\circ}$ mean difference between the first and second set of results indicating a high level of intra-rater reliability. Conclusions: The results suggest that the Hudl Ubersense App has high levels of concurrent validity (using the electrogoniometer as the gold standard) and intra-rater reliability, scoring better than previous research on the current clinical measuring device, the universal goniometer. The Hudl Ubersense App has clinical advantages over the electrogoniometer, so further research is recommended to determine its inter-rater reliability, acceptability, and appropriate clinical practice procedures.
\end{abstract}

Key words: Mobile application, range of movement, knee, concurrent validity, intra-rater reliability.

\section{Introduction}

In clinical practice, heath care professionals use goniometry to measure knee joint range of movement accurately during treatment of knee injury or after knee surgery. Measurements of range of movement help to determine the presence or absence of dysfunction, to provide evidence for clinicians on patient progress, and to guide future management [1, 2]. Measurements can also provide patients with

Corresponding author: Sara Aspinall BSc, MRes, MCSP Clinical Doctoral Researcher. John Beckwith Building, Loughborough University, EpinaL Way, Loughborough, LE11 3TU, UK. accurate feedback on their progress, which may aid motivation, and contribute to patient satisfaction [3]. Accurate measurement of range of movement is also important in research trials comparing effectiveness of different treatments at an impairment level.

In the clinical setting knee range of movement is generally measured using the universal goniometer, whereas in research studies, where greater precision is essential, electrogoniometer (EG) is preferable. The advantage of the universal goniometer is its accessibility, lack of expense, and simplicity [1], but its accuracy has long been questioned [4].

Edwards et al. [5] compared knee range of 
movement measurements using the universal goniometer with those recorded via radiography, and found that $22 \%$ of the universal goniometer measurements differed by $5^{\circ}$ or more from those made using an x-ray. They showed that intra- and inter-rater correlation coefficients were 0.92 and 0.79 respectively when measuring range of movement with a universal goniometer [5]. Trapper et al. [6] reported a $5.07^{\circ}$ mean difference between two measurements obtained by the same person using the universal goniometer, compared to a mean discrepancy of $1.15^{\circ}$ using a computer assisted navigation system. Inter-rater reliability consistently underperforms intra-rater reliability [7-9] with inter-rater differences up to $19^{\circ}$ [4], greatly exceeding what would be considered clinically acceptable.

Electrogoniometers enable clinicians to measure angles without identifying the moving centre of knee rotation in that potentiometers can consistently measure the angle between the axes of the femur and the tibia. The flexible electrogoniometer has been shown to have strong validity and reliability when measuring knee range of movement [10-12]. Test-retest accuracy is high at different times, on different days, and in different environmental conditions [11-15]. Piriyaptasarth et al. demonstrated that electrogoniometer intra-rater reliability was good to excellent, and inter-rater reliability was moderate. However, the assessor needs to apply the electrodes to the limb very carefully. The exact fitting of the electrogoniometer is essential for accuracy and this requires precision and training [11]. The superior validity and reliability of the electrogoniometer means that it is the chosen instrument for measuring knee range of movement in the research setting [16], although many studies still use the universal goniometer. However, there are some disadvantages for clinical practice because of expense, complexity of use and the need to attach electrodes, with resultant risks for transmission of infection.

Given the low reliability of the universal goniometer, the risks of infection, and expense of the electrogoniometer, currently (2019) approximately $£ 600[4,11]$, there is a need for a reliable and convenient method to measure knee range of movement [17]. In recent years the advent of smartphones and tablets has brought a range of new technological applications (apps) which could be used to measure joint range of motion (ROM), using the potentiometers and cameras built into the devices. Phone apps permit simple, fast and inexpensive measurements on devices (phone or tablet) which are often readily to hand [18]. It seems possible that these might also offer better and more reliable options than the universal goniometer and electrogoniometer. Given that the reliability and validity of instruments used to measure range of movement are important for evaluating clinical practice, and also for the interpretation of research results [4], it is important to establish the validity and reliability of these apps [19].

The Hudl Ubersense App (HUA) is marketed as a coaching tool that provides feedback on technique and movement to help an athlete improve their performance [20]. Possession of a smartphone is common place amongst clinicians and departments often have tablet devices available. There is no charge to use the app.

The app generates a video which can be frozen as a still image. Lines are applied to the joint axes in the photograph from which the app calculates the joint angle. Once a joint has been photographed the angle of the joint can be checked or re-measured at any time by other professionals, improving potential inter-tester reliability and providing photographic records for tracking range of movement over time, facilitating greater assessor transparency [21, 22]. Furthermore, camera-based measurements have the benefit of not requiring contact with the patient's skin, which minimises infection risk in the clinical setting and they may help to improve patient adherence to treatment by showing the patient sequential pictures demonstrating the change in range of movement [22]. 
The purpose of this research is to assess the concurrent criterion validity of the App as a measuring instrument for knee range of movement, by comparing it to the recognised gold-standard electrogoniometer, and also to establish its intra-rater reliability. It is hypothesised that the App is a valid and reliable measuring instrument for knee range of movement when used by the same person.

\section{Materials and Methods}

The study was approved by Coventry University's Health and Life Sciences Ethics and Governance Committee. A male volunteer was recruited via word of mouth who met the inclusion criteria; unimpaired knee function, English speaking, and aged between 19-60 years of age. Written informed consent was obtained from the participant. The experimenter was a physiotherapist currently in clinical practice.

The electrogoniometer used was a Twin Axis Goniometer SG150 (Serial Number: 83502 2911) which was used with the Angle Display Unit ADU301 (Fig. 1). The electrogoniometer was calibrated as per the manufacturer's guidance. The values of the electrogoniometer were, on average, $1^{\circ}$ above the universal goniometer.

To allow accurate measurements to be taken and reduce user error, three bony landmarks were marked by crosses (using an indelible marker) on the participant's skin (see Fig. 2): at the distal flare of the greater trochanter, at the lateral condyle of the tibia in line with the head of the fibula, and at the proximal flare of the lateral malleolus. A line was drawn on the distal third of the femur and on the proximal third of the tibia where the identified bony landmarks aligned using a metal metre rule. The electrogoniometer was then fixed with double-sided tape onto the lines drawn on the skin.

Errors might be made due to parallax in transposing 3D to 2D images, so standardised procedures were used to ensure that the device taking the images was parallel to the measured limb. The setup of the camera and subject position (seated) was standardised throughout the experiment following similar procedures to those carried out by Naylor et al. [21]. To further improve the standardisation of this procedure the tablet (Samsung Galaxy Tab 2) was set to be vertical using a spirit level. To ensure the measuring tablet was perpendicular to the floor, two plumb lines and marking tape were used (see Fig. 3). The chair was set parallel to this marked line. This "squaring system" ensured the image (knee joint) was $90^{\circ}$ to the tablet view finder and that the $2 \mathrm{D}$ image taken was not distorted by problems of parallax.

The participant was assessed on 20 different knee

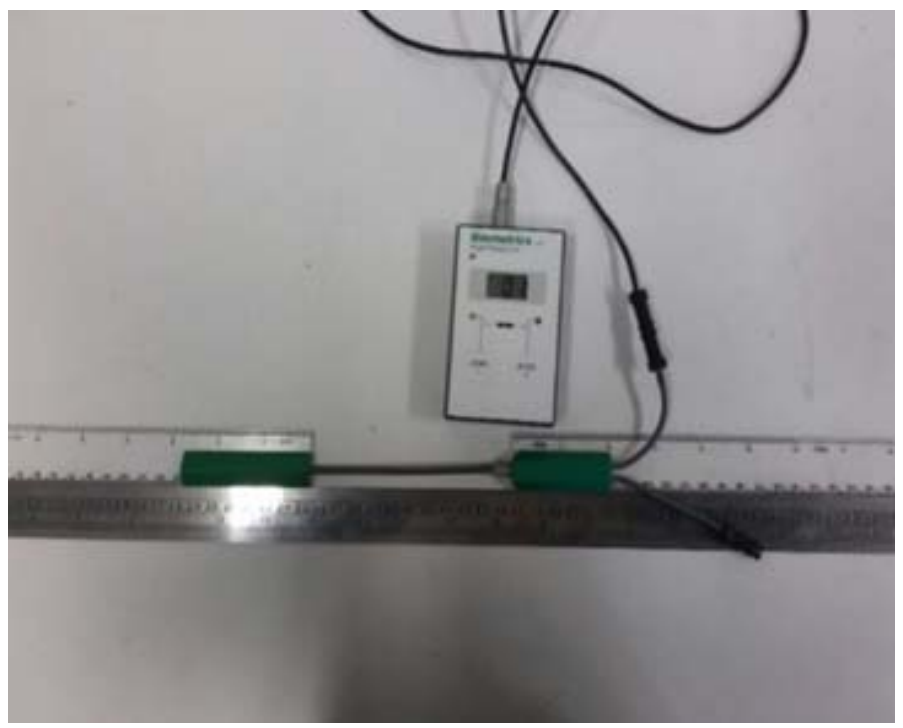

Fig. 1 Calibration of the electrogoniometer. 


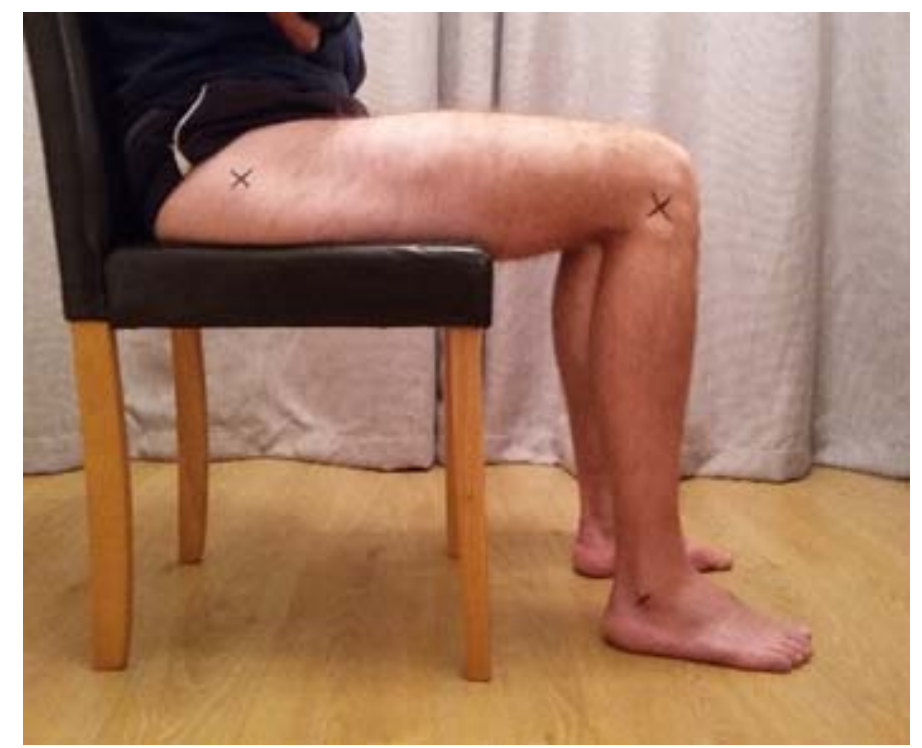

Fig. 2 Location of bony landmarks.

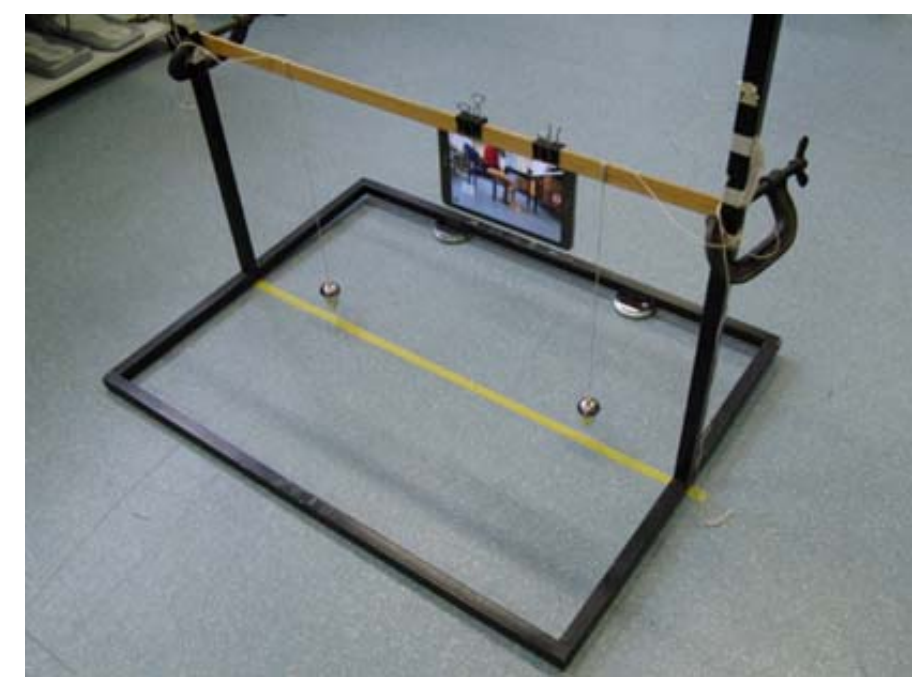

Fig. 3 The standardised set up procedure.

angles over the clinical range expected (i.e. $35^{\circ}-130^{\circ}$ ), in a pre-set determined random order, to which the assessor was blinded. The participant moved his knee to the prescribed angles using the electrogoniometer, and the assessor took measurements using the App (see Fig. 4 for display on app).

Data were analysed using a Bland-Altman plot, which presents the differences between individual measurements on two instruments, avoiding the loss of detail in methods that use average levels of agreement [23]. The mean and standard deviations (SD) of these differences enable an estimation of how far apart measurements by the two instruments are, and indicate their level of agreement. The pre-set level of agreement was that a minimum $95 \%$ of measurements taken by the App should agree with those of the electrogoniometer by less than $5^{\circ}$.

\section{Results}

\subsection{Trial 1}

In the first trial of 20 randomised knee angles, 19 of the app readings (95\%) differed by less than $5^{\circ}$ from the corresponding electrogoniometer readings (Table 1). All but one of the range of movement measurements were recorded as greater when using the 


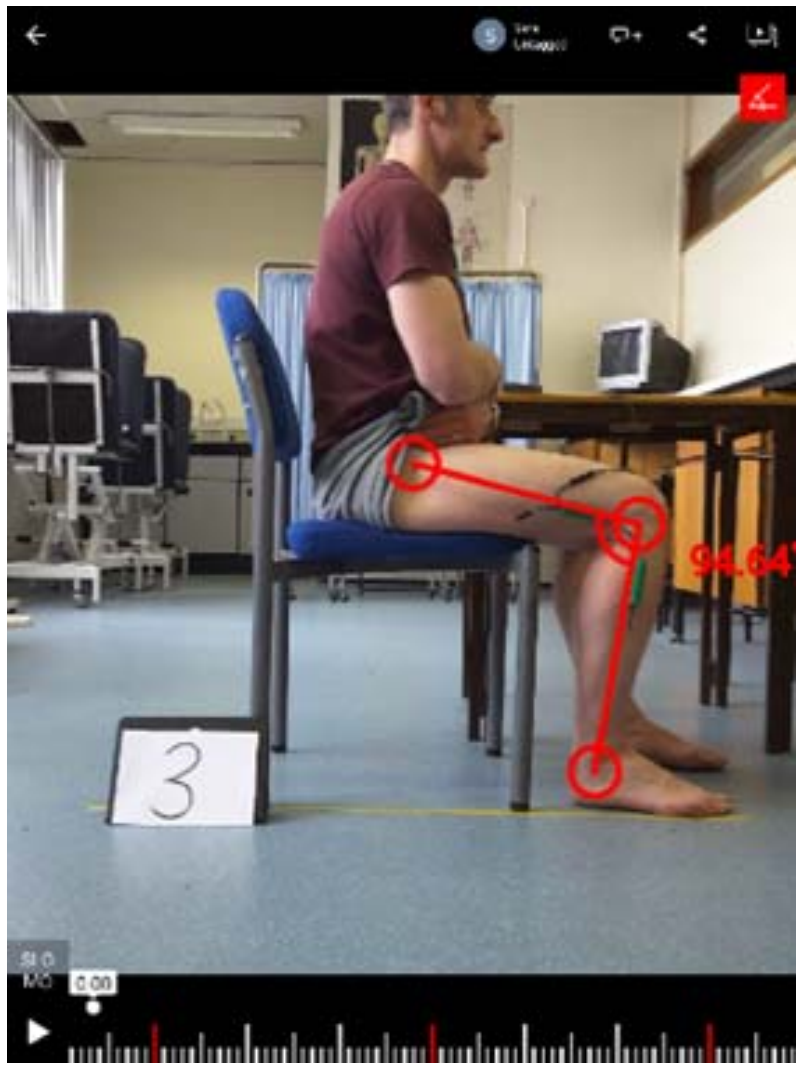

Fig. 4 App calculating knee angle.

Table 1 EG and HUA measurements from trial 1 (EG “set up in the seated position").

\begin{tabular}{lllll}
\hline Sequence & EG angle $\left(^{\circ}\right)$ & HUA angle $\left(^{\circ}\right)$ & Mean $\left(^{\circ}\right)$ & Difference $\left(^{\circ}\right)$ \\
\hline 1 & 40 & 38 & 39 & 2 \\
2 & 70 & 68 & 69 & 2 \\
3 & 80 & 82 & 81 & -2 \\
4 & 120 & 114 & 117 & 6 \\
5 & 35 & 34 & 34.5 & 1 \\
6 & 74 & 74 & 74 & 0 \\
7 & 99 & 96 & 97.5 & 3 \\
8 & 60 & 60 & 60 & 0 \\
9 & 45 & 45 & 45 & 0 \\
10 & 84 & 82 & 83 & 2 \\
11 & 114 & 111 & 112.5 & 3 \\
12 & 50 & 47 & 48.5 & 3 \\
13 & 105 & 102 & 103.5 & 2 \\
14 & 54 & 52 & 51 & 1 \\
15 & 64 & 63 & 63.5 & 4 \\
16 & 109 & 105 & 107 & 1 \\
17 & 131 & 130 & 130.5 & 1 \\
18 & 95 & 94 & 94.5 & 1 \\
19 & 126 & 125 & 125.5 & 1 \\
20 & 90 & 89 & 89.5 & 1.75 \\
Mean $\left({ }^{\circ}\right)$ & 82.3 & 80.6 & 81.3 & \\
SD $\left(^{\circ}\right)$ & & & & 1.77 \\
\hline
\end{tabular}


electrogoniometer compared to the app. Eighteen (90\%) of the data points fell within \pm 1.96 SD limits specified in the Bland-Altman plot (Fig. 5). Although this plot might suggest higher differences at larger angles, the intra-class correlation coefficient between the two instruments was 0.997 or higher in both of the trials.

\subsection{Trial 2}

In the second trial of 20 randomised knee angles, all 20 readings (100\%) taken by the app differed from the corresponding electrogoniometer readings by less than $5^{\circ}$ (Table 2). All but two readings were higher when measured by the electrogoniometer. All except one reading (95\%) were within the \pm 1.96 SD limits specified in the Bland-Altman plot (Fig. 6) which may again show slightly elevated differences at larger angles.

\section{Discussion}

The results of the two trials show high levels of agreement between the App and the electrogoniometer when used to measure knee angles between $35^{\circ}$ and $130^{\circ}$ under specific conditions. Thirty nine of the forty measurements of knee range of movement (97.5\%) made by the App differed from the measurements made by the electrogoniometer by less than $5^{\circ}$, and this indicates high levels of concurrent validity. This result satisfied the pre-set standard that $95 \%$ of readings should be within $5^{\circ}$, and is better than that found in research testing the universal goniometer [6] (previous research observed that $22 \%$ of the universal goniometer measurements differed by $5^{\circ}$ or more [5]). All but 3 readings fell within the \pm 1.96 SD limits indicated on the Bland-Altman plots to show levels of agreement [24].

The results of trial 1 were very similar to trial 2 , with the mean difference between the methods of measurement falling from $1.75^{\circ}$ to $0.80^{\circ}$, indicating much higher levels of intra-rater reliability than those found with the universal goniometer [6]. The findings have significant implications for clinical practice as the app is simple to use, cheap and potentially largely

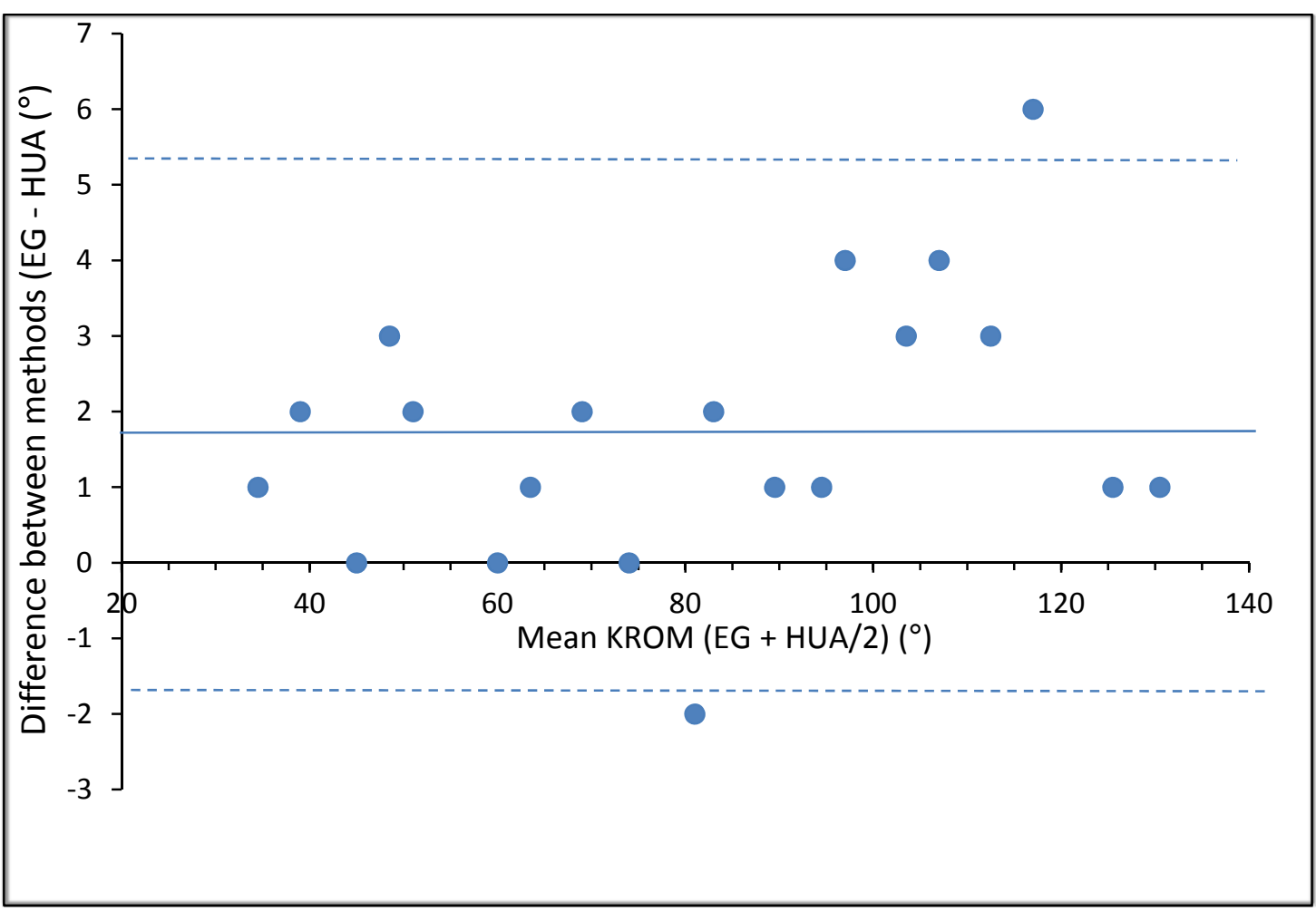

Fig. 5 Bland-Altman plot of electrogoniometer knee range of movement and app knee range of movement (trial 1). 

Measurement of Knee Range of Movement

Table 2 Electrogoniometer and app measurements from trial 2.

\begin{tabular}{lllll}
\hline Sequence & EG angle $\left(^{\circ}\right)$ & HUA angle $\left(^{\circ}\right)$ & Average $\left(^{\circ}\right)$ & Difference $\left(^{\circ}\right)$ \\
\hline 1 & 75 & 73 & 74 & 2 \\
2 & 49 & 49 & 49 & 0 \\
3 & 35 & 34 & 34.5 & 1 \\
4 & 80 & 78 & 79 & 2 \\
5 & 130 & 130 & 130 & 0 \\
6 & 90 & 87 & 88.5 & 3 \\
7 & 110 & 108 & 109 & 2 \\
8 & 69 & 69 & 69 & 0 \\
9 & 104 & 105 & 104.5 & -1 \\
10 & 45 & 45 & 45 & 0 \\
11 & 95 & 95 & 95 & 4 \\
12 & 116 & 112 & 114 & 0 \\
13 & 55 & 55 & 55 & 0 \\
14 & 86 & 86 & 86 & -1 \\
15 & 65 & 66 & 65.5 & 1 \\
16 & 40 & 39 & 39.5 & 2 \\
17 & 124 & 122 & 123 & 1 \\
18 & 100 & 99 & 99.5 & -2 \\
19 & 59 & 61 & 60 & 2 \\
20 & 120 & 118 & 119 & 0.80 \\
Mean $\left(^{\circ}\right)$ & 82.3 & 81.6 & 81.95 & 1.47 \\
\hline SD $\left(^{\circ}\right)$ & & & & \\
\hline
\end{tabular}

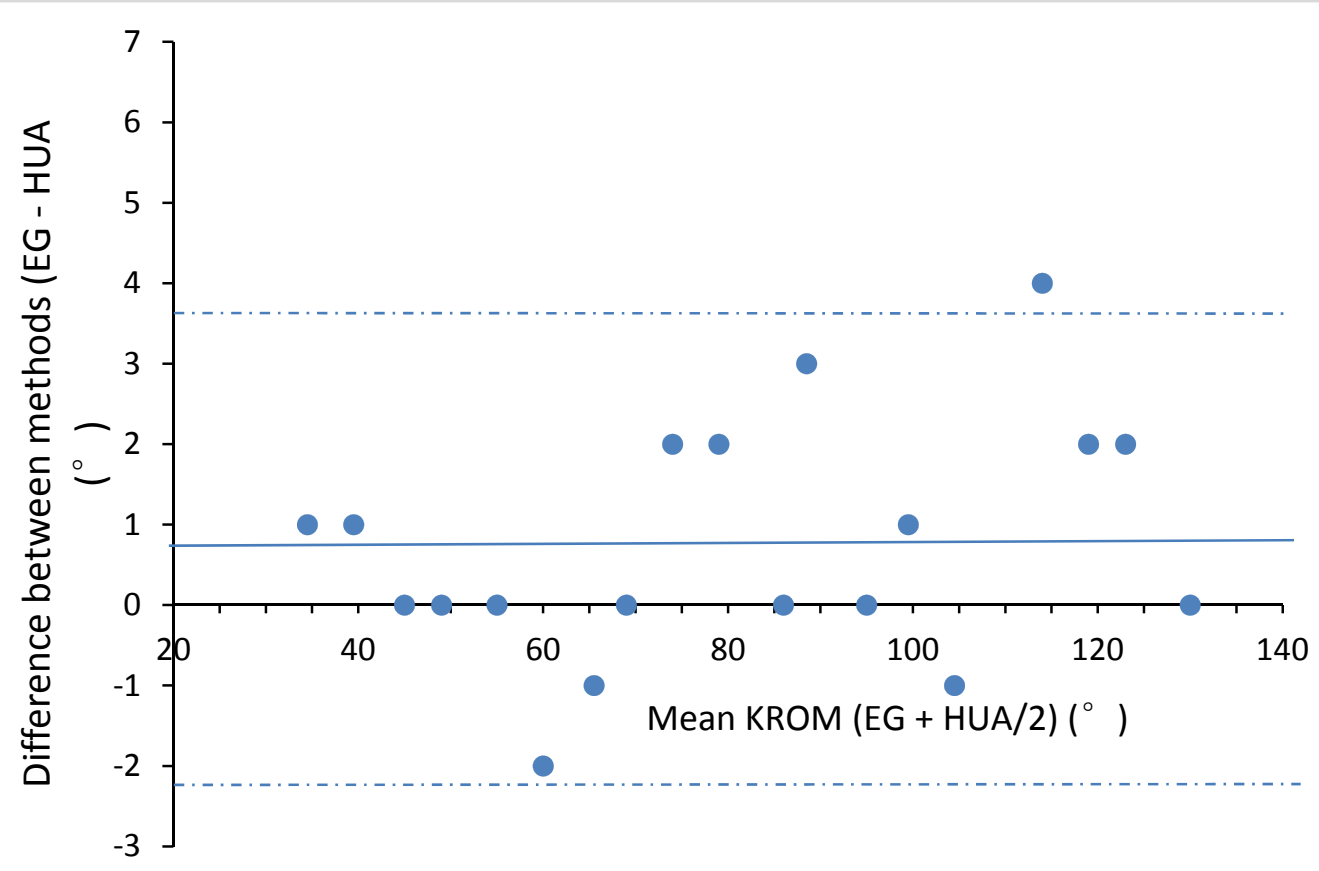

Fig. 6 Bland-Altman plot of electrogoniometer knee range of movement and the App knee range of movement (trial 2). 
accessible; advantages shared with the universal goniometer mean that it could potentially replace the universal goniometer in the clinical setting.

There was an improvement in levels of agreement between electrogoniometer and App readings in trial 1 and trial 2 from a mean difference of $1.75^{\circ}$ to $0.80^{\circ}$. The maximum and minimum limits of agreement (set by the Bland-Altman approach at $\pm 1.96 \mathrm{SD}$ ) for trial 1 came out at $-1.7^{\circ}$ and $5.2^{\circ}$ (a range of $6.9^{\circ}$ ), but the range between these decreased in trial 2 to $5.8^{\circ}\left(-2.2^{\circ}\right.$ to $3.6^{\circ}$ ), indicating narrower limits of agreement. The improvement in results from trial 1 to trial 2 may be due to learning effects and familiarisation of the tester to the measuring device, for example in more accurately drawing the axes with the App. To confirm this familiarisation effect and other aspects of intra-rater reliability, further research with a larger sample is required. Experience from this initial study suggests a practice session involving 20 measurements may be sufficient to familiarise a user with the app. Additional research is necessary to see if further improvements would be possible with further use, or whether 20 measurements are sufficient for familiarisation.

\section{Conclusions}

The results of this study give rise to the hope that the App may be superior to the universal goniometer for use in clinical practice. Further research needs to be carried out to verify these results. Although the results of this study are within the clinically significant level of $5^{\circ}$ of error, the methods employed involved stringent standardisation procedures not practical in the clinical setting.

\section{Limitations of the Study}

This was a small study under rigorous conditions testing concurrent validity and intra-rater reliability of a new measuring device for knee range of movement. The results need to be tested over a larger data set to see if these results are repeatable.
In particular, it is impossible to see from the small data set whether the levels of agreement are similar over the whole range of measurement. A very small tendency for the differences between the measuring tools to be smaller or negative at lower flexion angles, and more strongly positive at higher flexion angles, may be detected in the Bland-Altman plots (Figs. 5 and 6), indicating that the electrogoniometer slightly overestimates the higher flexion angles or that the app underestimates them. A larger sample of data points would enable a rigorous test for the presence or absence of this tendency.

The rigorous methods used to avoid problems of parallax which might have created error in making the photographic 2D record would not be possible in clinical practice. Experiments to repeat the measurements under clinical conditions are necessary to assess the metrics of the App as it would be used.

\section{Recommendations for Future Research}

This research needs to be repeated with a larger data set to assess for variations in levels of agreement between the two methods of measurement across the range of knee range of movements.

It is also recommended that a similar study with less standardisation of the position of the electronic device and of the subject is required, typical of what would happen in the clinical situation or in the patient's home. This would indicate whether the 3D picture could accurately be transposed to $2 \mathrm{D}$ in a less formal environment.

This study focused on one healthy subject, who was not experiencing any knee pathology. Further research should be carried out involving a larger number of subjects with varying body shapes and sizes to ascertain whether these present problems in identifying bony landmarks which in turn affect angle measurements. A study involving target populations such as people with knee arthroplasties would be beneficial to assess the app's accuracy when measuring swollen joints. 
A study assessing the inter-rater reliability of the app is also required. Some aspects of inter-rater reliability are much easier to check using the app since a photographic record would be available to compare assessors' processing. The app also has the potential for use at home by patients. Inter-rater reliability needs to be tested with service users and carers for use in telemedicine and for home monitoring, as well as among health professionals. Such home use could give service users greater independence and self-responsibility to record their own range of movement. Telemedicine, in which users could send accurate readings of their own range of movement to their consultant or health professional, has the potential to avoid the costs and inconvenience of travel to unnecessary face-to-face check-ups.

The app shows high levels of concurrent validity and intra-rater reliability for measuring knee range of movement on initial testing. Further research is required to assess more fully whether this App can become a valid, reliable, and useful clinical measuring tool.

\section{Declaration of Interest}

The authors report no conflicts of interest.

\section{Acknowledgements}

The authors would like to express their thanks to Roy Petticrew (senior technician for the CU School of Health and Life Sciences) for his time and expertise in conducting the study. Author Sara Aspinall completed this work as part of an MSc by research supported by the National Institute for Health Research (NIHR). This research did not receive any specific grant from funding agencies in the public, commercial, or not-for-profit sectors.

\section{References}

[1] Milanese, S., Gordon, S., Buettner, P., Flavell, C., Ruston, S., Coe, D., et al. 2014. "Reliability and Concurrent Validity of Knee Angle Measurement: Smart Phone App Versus Universal Goniometer Used by Experienced and
Novice Clinicians.” Man Ther.19 (6): 569-74.

[2] Werner, B. C., Holzgrefe, R. E., Griffin, J. W., Lyons, M. L., Cosgrove, C. T., Hart, J. M., et al. 2014. "Validation of an Innovative Method of Shoulder Range-of-Motion Measurement Using a Smartphone Clinometer Application.” J Shoulder Elbow Surg. 23 (11): e275-82.

[3] Lavernia, C., D’Apuzzo, M., Rossi, M. D., and Lee, D. 2008. "Accuracy of Knee Range of Motion Assessment after Total Knee Arthroplasty.” J Arthroplasty 23 (6 Suppl 1): 85-91.

[4] Lenssen, A. F., van Dam, E. M., Crijns, Y. H., Verhey, M., Geesink, R. J., van den Brandt, P. A., et al. 2007. "Reproducibility of Goniometric Measurement of the Knee in the In-Hospital Phase Following Total Knee Arthroplasty.” BMC Musculoskelet Disord 8: 83.

[5] Edwards, J. Z., Greene, K. A., Davis, R. S., Kovacik, M. W., Noe, D. A., and Askew, M. J. 2004. "Measuring Flexion in Knee Arthroplasty Patients.” J Arthroplasty 19 (3): 369-72.

[6] Trappler, R. E., Smith, G., Goldberg, J., and Parvizi, W. J. H. 2009. "Knee Range of Motion: Can We Believe the Goniometer Reading?” Orthopaedic Proceedings 91-B (SUPP I). Accessed May 09, 2019. http://www.bjjprocs.boneandjoint.org.uk/content/91-B/S UPP_I/6.2.

[7] Watkins, M. A., Riddle, D. L., Lamb, R. L., and Personius, W. J. 1991. "Reliability of Goniometric Measurements and Visual Estimates of Knee Range of Motion Obtained in a Clinical Setting.” Phys Ther. 71 (2): 90-6.

[8] Cleffken, B., van Breukelen, G., Brink, P., van Mameren, H., and Olde Damink, S. 2007. "Digital Goniometric Measurement of Knee Joint Motion. Evaluation of Usefulness for Research Settings and Clinical Practice.” Knee. 14 (5): 385-9.

[9] Brosseau, L., Balmer, S., Tousignant, M., O’Sullivan, J. P., Goudreault, C., Goudreault, M., et al. 2001. "Intra- and Intertester Reliability and Criterion Validity of the Parallelogram and Universal Goniometers for Measuring Maximum Active Knee Flexion and Extension of Patients with Knee Restrictions.” Arch Phys Med Rehabil. 82 (3): 396-402.

[10] Piriyaprasarth, P., Morris, M. E., Winter, A., and Bialocerkowski, A. E. 2008. "The Reliability of Knee Joint Position Testing Using Electrogoniometry.” BMC Musculoskeletal Disorders 9 (1): 1-10.

[11] Rowe, P. J., Myles, C. M., Hillmann, S. J., and Hazlewood, M. E. 2001. "Validation of Flexible Electrogoniometry as a Measure of Joint Kinematics.” Physiother 87.

[12] Bronner, S., Agraharasamakulam, S., and Ojofeitimi, S. 2010. "Reliability and Validity of a New Ankle Electrogoniometer.” J Med Eng Technol. 34 (5-6): 350-5. 
[13] Bevans, J. S. 1993. "Repeatability Study Using the Electrogoniometer.” J Br Podiat Med 48: 137-41.

[14] Shiratsu, A., and Coury, H. J. 2003. "Reliability and Accuracy of Different Sensors of a Flexible Electrogoniometer.” Clin Biomech 18 (7): 682-4.

[15] Biometrics. 2002. Goniometer and Torsiometer Operating Manual. Gwent, UK: Biometrics.

[16] Reese, N. B., and Bandy, W. D. 2009. Joint Range of Motion and Muscle Length Testing. 2nd ed., edited by Bandy, W., Saunders.

[17] Curtis, E., and Drennan, J. 2013. Quantitative Health Research: Issues and Methods. 1st ed., edited by Curtis, E., and Drennan, J., Open University Press.

[18] Ockendon, M., and Gilbert, R. E. 2012. "Validation of a Novel Smartphone Accelerometer-Based Knee Goniometer.” J Knee Surg. 25 (4): 341-5.

[19] Jones, A., Sealey, R., Crowe, M., and Gordon, S. 2014. "Concurrent Validity and Reliability of the Simple Goniometer iPhone App Compared with the Universal Goniometer.” Physiother Theory Pract. 30 (7): 512-6.
[20] Weiler, R. 2016. "Ubersense Coach App for Sport Medicine? Slow Motion Video Analysis (Mobile App User Guide).” Br J Sports Med. 50 (4): 255-6.

[21] Naylor, J. M., Ko, V., Adie, S., Gaskin, C., Walker, R., Harris, I. A., et al. 2011. "Validity and Reliability of Using Photography for Measuring Knee Range of Motion: A Methodological Study.” BMC Musculoskelet Disord 12 (77): 473-9.

[22] Milani, P., Coccetta, C. A., Rabini, A., Sciarra, T., Massazza, G., and Ferriero, G. 2014. "Mobile Smartphone Applications for Body Position Measurement in Rehabilitation: A Review of Goniometric Tools.” PM R. 6 (11): 1038-43.

[23] Bland, J. M., and Altman, D. G. 1986. "Statistical Methods for Assessing Agreement between Two Methods of Clinical Measurement.” The Lancet 327 (8476): 307-10.

[24] Altman, D. G., and Bland, J. M. 1995. "Absence of Evidence Is Not Evidence of Absence.” BMJ 311 (7003): 485. 